\title{
Methods of Promoting Professional Agency at Work
}

\author{
Satu Kalliola ${ }^{1}$ (D) and Salme Mahlakaarto ${ }^{2, *}$ \\ 1 Faculty of Social Sciences, Tampere University, Kalevantie 4, 33014 Tampere, Finland; \\ satu-sisko.kalliola@tuni.fi or satu.s.kalliola@gmail.com \\ 2 ID Mahlakaarto Ltd. (Private Company), Kauppakatu 14 B 11, 33210 Tampere, Finland \\ * Correspondence: salme@mahlakaarto.fi; Tel.: +358-45-3172673
}

Received: 29 October 2020; Accepted: 2 December 2020; Published: 4 December 2020

\begin{abstract}
In the midst of continuous changes in working life, finding a way to balance organizational demands and the needs of employees has become an important task. This task has highlighted the significance of agency and social interaction, as influencing factors that can enhance people's potential to meet new learning tasks. In the Scandinavian and Finnish contexts, research institutions, in cooperation with work organizations, have developed practical methods to promote agency and learning at work. The objective of this study is to evaluate the potential of two different workplace development methods, identity (ID) training, and participatory action research (PAR) using dialogue forums if combined and applied as a two-level approach. The study asks what the characteristics of these methods are in general and if there are any key characteristics that could support their combined application. The research question is answered by a qualitative descriptive analysis of the literature on organizations, agency, and applications of the methods. The results shed light on and emphasize the intertwining characteristics of the methods. The research concludes with the hypothesis - to be tested in further research - that the methods are necessary for each other and recommends a preliminary investigation on the prevailing organizational culture, as a resource for organization-specific modifications.
\end{abstract}

Keywords: agency; dialogue; work organization

\section{Introduction}

The environment of public sector organizations, consisting of many professional fields, like social services, health care, education, and teacher education, is characterized by a continuous lack of resources, new demands of active citizens, and, to some degree, an ideological emphasis on the privatization of public services. Rapid changes in working life also have far-reaching effects on employees' personal and social identities. Professional identities have been challenged by increased pressures to down-size, increased productivity, and structural reforms. As a consequence, employees are required to reshape their work-related identities, including their commitments and ideals at work, their relationships to their work organization, and their social relations with colleagues. In this situation, employees are at risk of losing their subjectivities at work. A loss of subjectivity is perceived by subjects themselves as a lack of a sense of meaningfulness at work, along with decreased commitment, negative emotions, increased tiredness, and, in extreme cases, utter exhaustion [1-3]. In 2008, long-term barometers measuring the perceived quality of Finnish working life showed that there was indeed a loss of a sense of meaningfulness at work, especially in the public sector [4]. Comparisons between the European and Scandinavian context further showed a remarkable intensification of work in the public sector, especially women's work. This situation indicates an urgent need to prevent further deterioration of the well-being of the employees in question. Since then, in 2018, Finnish employees experienced positive changes in their working life from the perspective of organizational changes and 
learning. For example, the percentage of employees that participated in training provided by their employers was $54 \%$ among male employees and $60 \%$ among female employees, and in addition to vocational and professional skills, the training covered also social interaction and collaboration skills [5]. Nevertheless, in order to avoid such negative consequences as those described above, subjects need to work with their identities in a way that allows them to redefine their subjectivities and become subjects in their work. Hence, development in a positive direction would mean that a person becomes an active agent and a self-creating subject. Considering the changes in working life affecting all members of work organizations, it is important to create and use workplace development methods that are beneficial for all actor groups at workplaces.

Becoming a subject takes place via an active process of subjectification, in which a person becomes an active subject for herself/himself and, through this, achieves autonomy and agency [6]. Phillips (2002) [7] has suggested a multi-level model of becoming a subject in a community; in such a process, the subject's active voice contributes to the discourse constructed by and maintained in the community. Becoming a subject in a community also means becoming an active agent, and this is based on the subject's reflective awareness of her/his identity position in the community. Such a subjectification/transformation requires subjects to enter deep-level, emotionally imbued, reflective, and constructive processes and, through these, to attain a new perspective-one that will bring new constructs into the individual's identity [8]. In order to promote employees' awareness of their subject positions, and of how these are constituted as part of their life history within actual work organizations, we need special kinds of educational programs to carry out employment-related identity work. In such programs, subjects need space and support, so that they can become aware of how their current work-related identity positions are constituted. Having achieved such awareness, they will then need further space for the redefinition of their new positions. In addition, new tools and strategies will be needed to cope with the demands of the work organization, especially in cases where the subject's well-being is threatened as a consequence of an excessive workload. With this situation in mind, we find it important to create and use workplace development methods that take into account both the needs of individuals and the demands of work organizations. Traditionally, the search for this kind of balance belongs to the field of strategic human resource management (SHRM), which emphasizes employee involvement as a productive factor and thus also the relationship between productivity and quality of working life (see, for example, [9]).

The research results indicate that one key factor in that balance is the nature of the employment relationship. In their classic research, Walton and McKersie (1965) [10] found that social interaction at the workplace level or between bargaining parties may cover such dimensions as integrative bargaining, meaning the search for mutual gains and solutions that benefit all parties. On the other hand, Heller (1998) [11], in his study on influence and discretion at work, argues that the key element in employee involvement is trust. Weick (1995) [12] brings forth the notion of sense-making in organizations: all individuals should have a right to discuss organizational changes from the point of view of the core question: What does this mean to us?

Based on the notions presented above, we define agency as a concept that refers to a variety of closely related phenomena, such as being an empowered subject at one's work, using discretion at work, or having an influence over work. Additionally, we conclude that all the aspects of working life presented above point towards a need for concrete joint forums for all members of work organizations to use their agency in addressing current and emerging issues. One way to answer to the challenges of a continuously changing working life is the various European Union (EU)-level and national-level development programs and projects that aim to increase efficiency and productivity, without compromising employee well-being.

This paper presents two methods, the ID training program and participatory action research (PAR) using dialogue forums, which have been practiced in Finland and also by the authors. The emphasis of the ID training program is on working with personal identities, with a particular focus on subjects' professional identities. The main aim of the program is to support participants' professional identities by 
strengthening their identity, which contributes to their agency. On the other hand, the dialogue-oriented PAR application calls for the use of agency at the individual level, and it also aims to enhance the potential for learning and change at the organizational level. There is a great amount of literature on these workplace development methods taken separately, although there have been few studies that consider them together. The most obvious explanation for this is that there has been little, if any, collaboration between the practitioners of each of the methods, so each method has been evaluated independently.

The objective of this paper is to determine the potential of applying these two methods in combination in relation to fulfilling the abovementioned individual and organizational demands, which promote professional agency at work. To meet this objective, we chose to use the two-level model of Phillips (2002) [7] as a vantage point. We understand that the ID training program may enhance employees' resources to use their active voice and that dialogue forums offer places where these choices can be expressed and heard. The concrete research task is to point out the basic characteristics of both methods and some of the key characteristics of a combined application of the two methods. In the qualitative analysis, descriptions of the methods are compiled separately, with a focus on their intertwining characteristics. These results are further elaborated to form a picture of the complementary and supporting characteristics associated with the combined application of the two methods.

\section{Materials and Methods}

The data and methods of this research are qualitative. A traditional literature review is used to create an overview of the changes in working life and their impacts on work organizations and possibilities to use agency. The literature on the methods that are the focus of this paper, ID training and participatory action research (PAR) using dialogue forums, is comprehensively gathered using criteria associated with the presentation of the methods, including both the underlying principles and practical details. All of the literature is listed in the references.

As a first stage of the analysis, a descriptive background summary is compiled of the learning demands, risks associated with maintaining agency, and the need to strengthen it in working life, as well as of classic notions of employee influence in work organizations, which builds an argument for the combination of the two workplace methods that form the focus of this paper. Secondly, a detailed presentation of the essential characteristics of the methods and their complementary features is compiled. Thirdly, the method presentations are interpreted in the framework of a two-level model that combines individual agency with its use in organizational-level dialogues. As the authors have practiced these methods, their experience and observations have a bearing on the interpretations, and the paper can thus be seen as one of the authors' own learning outcomes.

\section{Results}

\subsection{ID Training Program: The Method for Identity Work}

\subsubsection{Background}

The theoretical basis of the ID training program is subject-based empowerment, which, in this context, is defined as an increased awareness of oneself and one's relation to her/his social environment, as well as a strengthening of possibilities to affect one's own surroundings. Identity is regarded as an ongoing project of self-realization, formed via one's personal history and experience. Becoming a subject and becoming empowered are interpreted as processes that are partly co-directional and overlapping, shaping identities or functioning as tools for reconstructing identities.

The discussion and research on empowerment make a distinction between individual and organizational empowerment $[13,14]$. At the individual level, empowerment has been understood as an increase in inner strength and self-respect, together with better social skills and competencies to manage and develop one's own work and working conditions. At the organizational and community 
level, empowerment can be understood as a purposeful process in which an organization or community derives new resources. This means a shared experience of increased participation in a number of aspects of work: organizational goals, planning, decision-making, receiving information, becoming aware of one's roles, and obtaining social support. Individual and organizational empowerment are, in fact, closely intertwined, and there is evidence that the two aspects support one another $[15,16]$. This intertwining of individual and organizational empowerment may be interpreted as one example of Phillips' (2002) [7] multi-level model of subjectification producing agency. As individuals must learn to use their agency, organizations must also learn to use the potential of joint actions.

The tasks in the research [17-19] that form the basis for this method were to discover how participants experienced empowerment during the empowerment program and follow-up, to consider how their subjectivity developed within their work and in relation to the work organization, and to analyze the kinds of stories told by participants concerning their subjectivity. The empowerment program was set up to promote staff well-being in a particular hospital at the start of the 21st century. The research material consisted of portfolios from 19 individuals, video recordings, interviews, and semi-structured questionnaires. To meet the evaluative purposes [20], the material was gathered during and at the end of the program, as well as at six months, one year, and four years after the program had ended. In sub-studies within the research, thematic and narrative analytical methods were applied.

The results showed that empowerment in the workplace is a long-term process, involving an interaction between the individual and the environment. It is both intrapersonal and interpersonal in nature, and the person's own life-course and experience will be significant in either restricting or enabling the empowerment. Significant aspects of this include an increase in awareness, working with one's own boundaries, and activation towards identity work. The significant factors of subject-based empowerment are (1) inner strengthening, in which the important dimensions were a connection with the self, dealing with personal emotions, and an awareness of personal boundaries; and (2) a new identity position, manifesting as a new kind of functioning in one's relation to her/his environment. In conclusion, it can be stated that (1) achieving a deeper level of individuality and (2) self-understanding are important for individual subjectivity.

Individuals developed their relations with the organization. In this regard, the empowering of the participants meant, in particular, a strengthened recognition of the boundaries between the organization and the self. Over the long term, this seemed to mean a movement away from the experience of subjugation, marginalization, and coercion towards the strengthening of personal agency in the workplace. The participants were able to create a more realistic picture of themselves and the organization. They were able to recognize and defend their own boundaries and to make more choices that brought them satisfaction in their relationships with their work and the work organization.

While the experience of empowerment and individuals' chosen routes are individual matters, possibilities offered by the work community are important for the realization of one's own position and role. In the best-case scenario, this will mean shared empowerment for the community and the individual: the individual will contribute to the best of her/his ability, and the organization will have a worker whose wellbeing is secure and who is following the path of self-development. However, the result of empowerment can also be an increased awareness of the extent of one's frustration with the organization, the work, and the working conditions. This is more likely to happen in organizations that do not know how to benefit from having empowered employees using their agency. In such a case, empowerment can lead to the individual leaving the organization that provides no sense of satisfaction or refusing to take the roles that the organization offers. Next, we will describe the themes of the ID training program.

\subsubsection{An Identity Training Program: Themes and Implementation}

The aim of identity training is to support employees so that they can take on new roles in their work, develop personally, and strengthen their professionalism and mental resources while, at the 
same time, taking care of their own coping and well-being. The overall aim is to support the individual through long-term changes. Each group has around 6-12 participants. The training contains six workshops, each lasting $0.5-1$ day. The program as a whole lasts six months on average. In the identity training sessions, the themes are personal identity (ID-I), relationship identity (ID-We), organizational identity (ID-Together), and professional identity (ID-Professional) (See Figure 1).

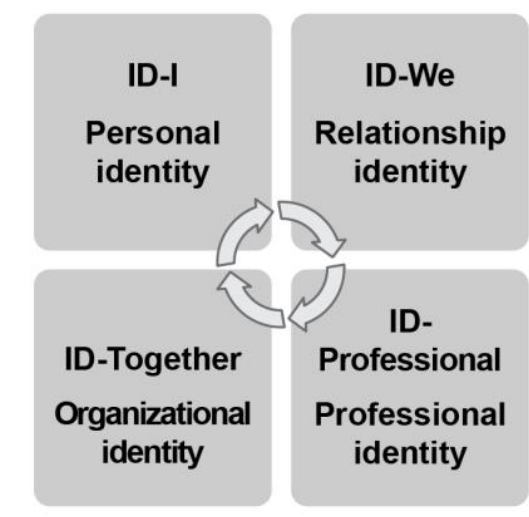

Figure 1. ID training program: the themes.

- ID-I: Personal identity

Personal identity consists of a person's own life-story, personal strengths, and developmental areas. The individual's own life, well-being, and work identity are bound up with each other. In ID-I, participants deal with their work identity in relation to their own life-course and individuality. In examining their life-story, they reflect on it via various theories of identity. They build up a picture of who they are and what their various special qualities and personal strengths are, considering also the kinds of life experiences they have had.

- ID-We: Relationship identity

Relationship identity consists of a person's social relations, roles, and relationships within her/his work community. Good social relations within the work community contribute significantly to the vital energy of the individual and the work community and create joy and relaxation within the work. A central element in ID-We is working on one's own interactional world and on the essentials of human interaction. In addition, the person's own skills are strengthened in encounters with others and in giving and receiving feedback. Beyond this, the aim is to increase awareness of how people's ways of organizing their own relationships affect relationships in the workplace.

- ID-Together: Organizational identity

Organizational identity consists of a person's position, opportunities, and ways to influence, belong to, and commit to the organization. An individual's relationship with the organization, including its mission and its dynamics, is important for understanding the relationship between that person and his/her work. At the heart of the ID-Together component are activities aimed at the individual's relationship with the organization and its functions. The participants work on the significance of their own work and on their awareness of their place within the organization and its dynamics.

- ID-Professional: Professional identity

Professional identity consists of a person's professional history, competencies, and fundamental values of his/her work. These play an important part in maintaining and strengthening work identity. In ID-Professional, we work on people's values and principles in relation to their work. We further consider their professional expertise and the directions in which it might develop. 
Autonomy and dependency are two significant driving forces of human identity. Autonomy prevails over personal and professional identities, while relationship and organizational identities are connected by a relationship of dependency. Human beings are social creatures that want to bond with their fellows and organizations. Additionally, they want to create themselves and build their own identity narratives.

During the training, we make use of narratives and include various kinds of whole-group activities and creative methods. These are based on stories, which are told in many different ways (including through sociodrama, psychodrama, pictorial expression, and writing). In the telling of these stories, social interaction within the group is important for giving rise to reflection and sharing. The group offers a space in which change can take place. Within the group, the participants create meanings connected with the fundamental questions of their own lives and, in so doing, construct new understandings and knowledge about themselves and their environment. Vocational skills and professionalism are absorbed as parts of the narratives created during the training. These narratives cannot be understood completely without understanding the ways the work organizations are run within the boundaries of organizational culture. In all cases, empowered agents need the right place and time to practice their agency, which emphasizes the significance of the ways work is organized and leadership is practiced.

The program also includes training materials and various tasks to promote deeper exploration. The tasks function as materials or as objects through which participants can consider issues as a total entity, something to be reflected on from the point of view of their own lives and identities. One line in the further development of ID training has focused on promoting educators' collective agency [21,22].

\subsection{Participatory Action Research (PAR) and Dialogue Forums}

In Finland, participatory action research (PAR) gained favor as a method for developing working life in the 1980s. Since then, action research has kept its position as a significant tool, especially in the enhancement of employee involvement (one way to express the possibilities for employees' agency) and learning at work, which are both integral parts of any organizational culture. One of the methods, communicative and participative action research using dialogue forums, is of Scandinavian origin [23]. The method, with roots in the era of workplace democracy, has gained favor, especially in Finnish municipalities, since 1991, but it has also been conducted in other public sector work organizations to create new practices. The materials of the original PAR projects have been analyzed in the course of conducting surveys on the quality of working life, qualitative interviews, and other evaluation practices, for example, [24,25].

The dialogue forum method is based on communication and interaction that is structured on many levels. Firstly, special PAR intervention forums, often called Dialogue Conferences or Work Conferences, are conducted according to certain patterns; and secondly, in all the phases of the conferences, all participants are supposed to follow the criteria for Democratic Dialogue. These criteria of Democratic Dialogue are also used as guidelines in all other project forums, like task forces, workplace meetings, and gatherings of occupational groups.

Dialogue Conferences may be used for many purposes. Most often, they are means to plan the future and to evaluate the progress of development projects. Conferences conducted according to the basic model, presented in this paper, last for 1.5-2 working days. In the hectic pace of the current working life, shorter versions have also been conducted. In the basic model of the method, the problems and flaws of the organizations are set aside for a moment, as the starting point is the desirable future. The visions of the desirable organizational futures will be formulated in homogeneous groups. Depending on the theme of the Dialogue Conference, the members of the groups may be, for example, representatives of the staff, the supervisors, and the management, students and teachers, or representatives of different occupational groups taking care of the same clients, like nurses and home care workers $[26,27]$. All the visions are brought to be discussed in a plenary, after which diagonal groups, consisting of representatives of all groups involved, start thinking about the concrete realization of the vision. What obstacles are there on the way to attaining the vision in question? Again, the results are discussed in a plenary. The conference continues by discussing the obstacles found by 
every diagonal group in freely formed groups, with the aim of finding ways to overcome the obstacles. After the plenary, the people who work together, that is, the "original organizational groups", will make use of all the earlier discussions and formulate concrete action plans for the future-sometimes for the near future and sometimes for a longer period of time. Usually, the conferences end with a plenary discussion, which makes a summary of the ideas brought forward, emphasizing the similarities and the differences in the experiences, and looks for common ground in order to highlight some concrete actions that can be taken immediately.

The first two phases (visions and obstacles) are very important for the grass root level employees because their proper conduct ensures that their voice will be heard. In addition, their voice is not only heard, but it is taken seriously, because the visions of every group in question will be given the same level of respect, and they all form a basis for further discussions and concrete planning.

During the group discussions, the researchers will see that the Democratic Dialogue criteria are followed. The criteria will have already been circulated to the participants, often together with the invitation to the conference. The main task is to ensure that everyone participates, and no one dominates the discussions. This is usually achieved by favoring those employees who are not used to expressing their opinions and who thus need support in developing their agency.

The status and nature of the Democratic Dialogue criteria are rather difficult to define. However, from a pragmatic point of view, they are a set of principles or obliging rules that work. The formulation provided in [23] (pp. 18-19) is as follows:

1. Dialogue is based on the principle of give and take, not one-way communication.

2. All concerned with the issue under discussion should have the possibility of participating.

3. Participants are under an obligation to help other participants be active in the dialogue.

4. All participants have the same status in the dialogue arenas.

5. Work experience is the point of departure for participation.

6. Some of the experience the participant has when entering the dialogue must be seen as relevant.

7. It must be possible for all participants to gain an understanding of the topics under discussion.

8. An argument can be rejected only after an investigation (and not, for instance, on the grounds that it emanates out of a source with limited legitimacy).

9. All arguments that are to enter the dialogue must be presented by the actors present.

10. All participants are obliged to accept that other participants may have arguments better than their own.

11. Among the issues that can be made subject to discussion are the ordinary work roles of the participants. No one is exempt from such discussion.

12. The dialogue should be able to integrate a growing degree of disagreement.

13. The dialogue should continuously generate decisions that provide a platform for joint action.

The emphasis on equality (criterion number 4) and work experience (criterion number 5) are important aspects of Democratic Dialogue in relation to the promotion of exerting influence and agency. Work experience, as the basis for participation, is connected to the significance of professional agency at work. Some other aspects (criteria 3 and 7) may be seen as facilitators of learning. The especial importance of criterion number 7 ("It must be possible for all participants to gain an understanding of the topics under discussion") seems to lie in the concrete focus both on exerting an influence and the learning of active agents in workplaces. Criterion number 7 is connected directly to learning opportunities and also to mutual learning (learning together, workplace learning). When everybody has to take a stand and talk to the others-managers and employees alike- the initial partial picture of the organization starts gaining new dimensions and new shades. However, this is a crucial point: there might be participants who need even more support in expressing their opinions and being professional agents, and this is the point where the ID training program is useful.

Finally, concerning the aspects of the Democratic Dialogue, it is important to remember criterion number 13, which emphasizes the significance of agreements. This is a means for changing words 
into concrete action. The explanation is that shared understandings about the need for change and about the tools to respond to that need will produce commitment, and efficient ways of working together may emerge. People seem to be willing to accept this, since they have a lot of experience with being confronted either with hierarchical orders or resistance, as expressions of the prevailing organizational culture.

\subsection{Combining the Identity Program and Dialogue Forums}

The foregoing descriptions of the characteristics of the two methods point out the supporting features of the ID training program and PAR using dialogue forums. When the ID training program has succeeded, the empowered organizational members need actual possibilities to use their agency. On the other hand, dialogue forums cannot work properly without people who are not only willing but also able to participate in constructive dialogues. Interpreted in the framework of Phillips' (2002) [7] multi-level model, the ID training program enables the participants to use their active voice in the discourse available in the organization, while the dialogue forums increase the availability of discourse and possibilities to construct and maintain it on significant issues. Thus, a functional interplay of these two methods may result in empowerment, learning, and organizational change in cases where dialogues result in joint action.

It is also possible to make further observations, for example, that the methods may be applied in complementary—if not necessary-ways. For example, the ideas of Rappaport (1995) and Speitzer (1995) on individual and collective empowerment point in this direction, if a work organization wants to rely on its own potential in deriving new resources.

Additionally, both descriptions refer to the constraining or promoting elements of the organizational culture regarding employee agency. In order to ensure the smooth running of the methods, a manager, facilitator of change, chief shop steward, action researcher or a consultant, or anyone applying these methods in collaboration with a work organization needs to know beforehand some basic facts about the history of the organization. Knowledge about the main characteristics of the organizational culture will help to fit the methods in the prevailing conditions. He or she should be able to recognize the power elites and other gatekeepers, the necessary organizational or sectoral borders to be crossed or bridged, and the potentially vulnerable groups or individuals who need special support in using their voice. This information is needed when decisions are made about actual issues to be dealt with, who should be invited to participate in dialogue forums, whether the potential participants are ready to participate, whether an ID training program should be organized before any dialogue forums have been established, or if it would be better to employ the two methods in parallel.

\section{Discussion}

This paper describes and analyzes the characteristics of two workplace development methods, ID training, and participatory action research (PAR), using dialogue forums. The main research task is to find out the key characteristics of the methods and investigate their combined application. The research task is fulfilled by conducting a descriptive qualitative literature analysis. The results emphasize the intertwining characteristics of the methods, and it is possible to interpret them as prerequisites for each other in work organizations, especially in work organizations with a history of having few possibilities to benefit from employee agency.

If the PAR and dialogue forums' requirements in terms of space, time, and place are fulfilled, the focus will shift towards the interaction and learning aspects. The notion of learning is closely connected to the idea of Democratic Dialogue as a whole. Democratic Dialogue may be seen as a demand for equal opportunities for understanding and learning about relevant issues in the workplace. This approach emphasizes the rights of employees to access knowledge that has been traditionally reserved for management [23]. On the other hand, while dialogue forums give individuals an opportunity to have their voice heard, individuals also require the strength to use that voice, and in many cases, ID training may be needed to strengthen the professional identity of participants, 
before dialogue forums can really work as platforms for mutual learning, making sense of organizational challenges [12], and shaping practical action.

While the two workplace development methods presented here have separate roots, their applications have, in addition to their intertwining characteristics, other common features. To start with, the ID training program may also be understood as a PAR application, since it usually requires the intensive involvement of a trainer from outside of the work organization and activities that would not take place without this involvement.

During these processes, many possibilities are offered to observe how the work organizations and their members act. People propose different interpretations and experiences from their subjective worlds. Thus, a particular process of the program takes shape uniquely within this process-a process wherein experiences are shared, and truth and awareness are created. The identity training program offers a many-layered process for work on identity. The identity narrative of each participant has a life and process of its own, and the task of the facilitator is to monitor and support the formation of this narrative. Another important aspect is the group and the atmosphere of exploration and creation that the group makes possible. Hence, it is important for this exploration that the atmosphere is sufficiently secure and that, in Heller's (1998) [11] words, trust is a prerequisite. PAR using dialogue forums calls for the same factors: people will not express themselves unless they can trust that their opinions will not be exploited later or if they have reason to think that the dialogue will not turn into joint action [24]. Within the group, the emergence of a common dialogue makes it possible to reach a broader understanding of oneself and of the surrounding reality, to become stronger, and also to arrive at an understanding of other people's experiences. Common reflection can also be seen as an opportunity for empowerment and for producing critical awareness and agency.

Since researchers and work organizations cooperate in the PAR approach, the paper contributes both to research communities and practitioners as well as decision and policymakers in the field of working life development in at least three ways:

Firstly, the paper is an attempt to concretize Phillips's (2002) [7] two-level model of becoming a subject with an active voice, which will be used and profited from in organization-level discourse. The research results, which may be summarized as defining the investigated methods in terms of supporting, complementing, or requiring each other, especially in work organizations with a history of little use of agency, form a hypothesis to be tested in further research or as a practice to be evaluated. The focus should be on offering a space, a time, and a place wherein individual identity work and dialogues at the organizational level can occur. The limitations of the study point in the same direction. Since the research results were produced by qualitative literature analysis, with a bearing on the authors' own experience, empirical research is needed.

Secondly, since the practicing of agency and Democratic Dialogue are based on agency, which cannot, by definition, be predicted beforehand, the methods cannot be copied unthinkingly or transferred wholesale between organizational environments. However, the methods are malleable enough to be modified accordingly.

Thirdly, since both methods are conducted in real organizational environments, their successful application requires becoming acquainted with the organization in question beforehand. Preliminary research on the organizational culture of the target organization is recommended, in consideration of the available resources. The results of this type of diagnostic research approach are needed to plan organization-specific modifications.

\section{Conclusions}

The two driving forces of current societies, globalization of economy and technological change, challenge work organizations to renew their modes of operations. Especially public sector organizations, characterized by professional, value oriented work of nurses, teachers and social workers, may be endangered by pressures of down-sizing and restructuration. Instead of these traditional measures, work organizations should learn to conduct flexible changes continuously. 
In order to prevent a loss of subjectivity of professional employees, and as a consequence, a weakened organizational commitment, during an era that requires actually more commitment than earlier, the application of special workplace development methods is recommended. The initiatives can be taken by organization- or profession-level actors, although initiatives by community level decision-makers and national level policy-makers could support the change considerably.

Individual level methods, for example identity (ID) training by an outside counsellor, or workplace and organization level methods, for example participatory action research (PAR) with dialogue forums, may be applied to promote professional agency that is needed to boost the renewal process. Although these methods can be applied separately, their combined use is recommended due to their complementary characteristics.

Author Contributions: Conceptualization, S.K. and S.M.; Methodology, S.K.; Investigation, S.K. and S.M.; Writing: Original Draft Preparation, S.K.; Visualization, S.M. All authors have read and agreed to the published version of the manuscript.

Funding: This research received no external funding.

Acknowledgments: We thank Anneli Eteläpelto for inviting us to collaborate on her research project, PROAGENT, Promoting Professional Agency in Education and Health Care Work, funded by the Academy of Finland in 2011-2014. We also thank her for organizing Symposium 11, Promoting professional agency at work, in the 7th International Conference on Researching Work and Learning in Shanghai, China, on 4-7 December 2011. Our participation in the symposium enabled us to present our idea of combining the identity program and dialogue forums to international audiences as a conference paper, which has served as the first version of this article [Kalliola, S. and Mahlakaarto, S. (2011) The methods of promoting professional agency at work. In H. Jian, 1. Deen, M.Songge, and P. Simin (Eds.) Proceedings of 7th international conference on researching work and learning, Shanghai: East China Normal University, 1141-1152] https://sites.google.com/site/rwl7proceedings/].

Conflicts of Interest: The authors declare no conflict of interest.

\section{References}

1. Greenglassa, E.R.; Burke, R.J.; Fiksenbaum, L. Workload and burnout in nurses. J. Community Appl. Soc. Psychol. 2001, 11, 211-215. [CrossRef]

2. Kirpal, S. Researching work identities in a European context. Career Dev. Int. 2004, 9, 199-221. [CrossRef]

3. Kirpal, S. Work identities of Nurses: Between caring and efficiency demands. Career Dev. Int. 2004, 9, 274-304. [CrossRef]

4. Ylöstalo, P.; Jukka, P. Työolobarometri [Working Life Barometer]; Työ- ja Elinkeinoministeriö: Helsinki, Finland, 2010.

5. Lyly-Yrjänäinen, M. Työolobarometri 2018 [Working Life Barometer 2018]; Työ- ja Elinkeinoministeriö: Helsinki, Finland, 2019.

6. Casey, C. The learning worker, organizations and democracy. Int. J. Lifelong Educ. 2003, 22, 620-634. [CrossRef]

7. Phillips, D.K. Female Preservice Teachers' Talk: Illustrations of subjectivity, visions of 'nomadic' space. Teach. Teach. Theory Pract. 2002, 8, 9-27. [CrossRef]

8. Leitch, R. Tackling the 'Iron maiden' of language in narrative inquiry: Creating the case for image-based narrative in stories of teachers' identities. In Proceedings of the European Conference for Educational Research, Crete, Greece, 25 September 2004.

9. Leitch, R. The Prodcutive Edge: A New Strategy for Economic Growth; W W Norton and Company, Inc.: New York, NY, USA, 2000.

10. Walton, R.E.; McKersie, R.B. A Behavioral Theory of Labor Negotiations. An Analysis of Social Interaction System; Cornell University Press: New York, NY, USA, 1965.

11. Heller, F. Influence at Work: A 25-Year Program of Research. Hum. Relat. 1998, 51, 1425-1456. [CrossRef]

12. Weick, K.E. Sensemaking in Organizations; Sage: Thousands Oaks, CA, USA, 1995.

13. Rappaport, J. Empowerment meets narrative: Listening to stories and creating settings. Am. J. Community Psychol. 1995, 23, 795-807. [CrossRef] [PubMed]

14. Spreitzer, G.M. Psychological, Empowerment in the Workplace: Dimensions, Measurement and Validation. Acad. Manag. J. 1995, 38, 1442-1465. [CrossRef] 
15. Styhre, A. Becoming empowered: Organization change in a telecom company. Int. J. Hum. Resour. Manag. 2004, 15, 1445-1462. [CrossRef]

16. Wallach, V.A.; Mueller, C.W. Job Characteristics and Organizational Predictors of Psychological Empowerment among Paraprofessionals within Human Service Organizations. Adm. Soc. Work 2006, 30, 95-115. [CrossRef]

17. Hänninen, S.; Eteläpelto, A. Promotion of professional subjectivities through the program of empowerment. In Proceedings of the 4th International Conference on Researching Work and Learning RWL, Sydney, Australia, 12-14 December 2005; Available online: http://www.rwlconferences.org/events/rwl4-sydney-australia-2005 (accessed on 17 September 2020).

18. Hänninen, S.; Eteläpelto, A. Promoting professional subjectivities and personal agency at work: The long-term influences of an empowerment programme. In Emerging Perspectives of Workplace Learning; Billet, S., Hartels, C., Eteläpelto, A., Eds.; Sense Publishers: Rotterdam, The Netherlands, 2008; pp. 97-112.

19. Mahlakaarto, S. Subjektiksi Työssä: Identiteettiä Rakentamassa Voimaantumisen Kehitysohjelmassa [Becoming a Subject at Work: Constructing Identity within a Program of Empowerment]; University of Jyväskylä: Jyväskylä, Finland, 2010.

20. Fetterman, D.M. A window in the heart and soul of empowerment evaluation: Looking through the lens of empowerment evaluation principles. In Empowerment Evaluation Principles in Practice; Fetterman, D.M., Wandesman, A., Eds.; Guilford Press: New York, NY, USA, 2005; pp. 1-26.

21. Hökkä, P.; Vähäsantanen, K.; Mahlakaarto, S. Teacher educators' collective agency and identity re-negotiation amid tensioned work practices. In Teaching for Tomorrow Today; Garbert, D., Ovens, A., Eds.; Edify Ltd.: Auckland, New Zealand, 2015; pp. 78-87.

22. Hökkä, P.; Vähäsantanen, K.; Mahlakaarto, S. Teacher educators' collective professional agency and identity-Transforming marginality to strength. Teach. Teach. Educ. 2017, 63, 36-46. [CrossRef]

23. Gustavsen, B. Theory and practice: The mediating discourse. In Handbook of Action Research: Participatiave Inquiry and Practice; Reason, P., Bradbury, H., Eds.; Sage: London, UK; Thousand Oaks, CA, USA; New Delhi, India, 2001; pp. 17-26.

24. Kalliola, S.; Nakari, R.; Pesonen, I. Learning to make changes: Democratic dialogue in action. J. Work. Learn. 2006, 18, 464-477. [CrossRef]

25. Kalliola, S.; Heiskanen, T.; Kivimäki, R. What Works in Democratic Dialogue? Soc. Sci. 2019, 8, 101. [CrossRef]

26. Kalliola, S. Self-designed teams in improving public sector performance and quality of working life. Public Perform. Manag. Rev. 2003, 27, 110-122.

27. Kalliola, S.; Nakari, R. Renewing occupational cultures-Bridging boundaries in learning spaces. Int. J. Educ. Res. 2007, 46, 190-203. [CrossRef]

Publisher's Note: MDPI stays neutral with regard to jurisdictional claims in published maps and institutional affiliations.

(C) 2020 by the authors. Licensee MDPI, Basel, Switzerland. This article is an open access article distributed under the terms and conditions of the Creative Commons Attribution (CC BY) license (http://creativecommons.org/licenses/by/4.0/). 